\section{The expanding spectrum of osteopathic research}

In the newly released book, "Osteopathic research: Growth and development," edited by George W. Northup, D.O., Wilbur V. Cole, D.O., discusses the nature of osteopathic research and how it has changed over the years. He observes, "Early research focused on one phase of osteopathic medicine; namely, structural diagnosis and manipulation. Although research into structural diagnosis and manipulation has continued, the direction of basic research into osteopathic principles has moved from histopathologic studies using the physiological apparatus that was available at the time to neurophysiologic and neurochemical studies. Clinical research, for the most part, no longer is directed toward the comprehension of mechanisms that are directly or indirectly associated with somatovisceral disorders; it has branched into other biologic and physiologic areas of investigation." The two articles featured in the Original Contributions section of this issue of JAOA are representative of these areas described by Cole.

In "Clinical biomechanic correlates for cervical function: Part II. A myoelectric study," Vorro and Johnston report findings of electromyographic activity in subjects with somatic dysfunction of the cervical spine, as characterized by asymmetric restriction to cervical sidebending. Their data reveal that muscles in the asymmetric group were slower to initiate action and were reduced in time and strength of contraction. This paper, which begins on page $353 / 83$, is part of a continuum of excellent investigations into the nature of somatic dysfunction.

At the other end of the spectrum of osteopathic medical research is the contribution by Chan and associates. In "Retarded cleavage following in vitro fertilization of mature human oocytes," the authors report 13-months' experience with 29 patients at the University of Medicine and Dentistry of New Jersey-School of Osteopathic Medicine affiliate, Kennedy Memorial Hospital-University Medical Center. Their observations on the parameters associated with successful in vitro fertilization and normal, unretarded cleavage of fertilized oocytes represent important new clinical information, albeit in a specialized area of medical science. The paper begins on page $368 / 99$.

These original contributions demonstrate both the depth and breadth of the research that is being conducted at the colleges of osteopathic medicine and their affiliated teaching hospitals.

THOMAS W. ALLEN, D.O., FACOI

\section{Seek health!}

Throughout the years, several of Andrew Taylor Still's aphorisms have been quoted and requoted with near-ritualistic fervor. However, one of the quotes of Still that is infrequently mentioned is "seek health-anyone can find disease." Still had the foresight to imply that health was a positive quality of the human condition, rather than the mere absence of disease.

Today, we read about the "wellness concept" in our newspapers, magazines, and even in medical journals. The concept of wellness, as a positive quality, is synonymous with what we refer to as health.

However, wellness is not something that can be given to a person solely through a multicolored capsule or some magic liquid potion. There is an unfortunate tendency among some people to avidly support the wellness concept while at the same time they look to the medical sciences to provide it, without any personal involvement or individual effort to change lifestyle or nefarious habits. Millions of people overeat, continue to smoke (endangering their own health as well as the health of others), abuse drugs, or become victims of alcoholism. At the same time, they expect medical science to find better treatments for their tobaccoinduced emphysema or lung cancer or other healthrelated problems. The patient is not only part of the problem, but a necessary part of the solution. The patient must not abrogate his or her own role in the quest for health.

Much is written and said about the high cost of medical care. The most remarkable reduction in 
this cost could be accomplished if a large segment of the public were to change their lifestyles, give up known health hazards, and become not just treated patients, but patients who are an integral part of the search for health.

When Andrew Taylor Still counseled that one should "seek health," he did not mean it as a platitude. It was a very important observation directed not only to physicians, but to patients as well. And only now, more than 100 years later, the depth of that simple statement is being realized.

\section{GEORGE W. NORTHUP, D.O., FAAO}

\section{The deposition}

A recent paperback book, "Malpractice depositions: Avoiding the traps" (Medical Economics Books, Oradell, New Jersey), describes in considerable detail the critical importance of depositions taken during professional liability cases. The phenomenal interest in this book is exemplified by the fact that over 2,000 prepublication orders were placed.

Many physicians fail to understand the impact of the deposition. Because 97 percent of all malpractice cases are settled before they go to trial, depositions weigh heavily on the resultant decisions.

The deposition's key value is succinctly stated by the authors, Raymond M. Fish, Ph.D., M.D., and Melvin E. Ehrhardt, M.D., J.D., in the first sentence of the book: "You can easily lose your malpractice case during the deposition, a meeting in which your patient's attorney questions you in order to get information that will support the claim of malpractice." They suggest ways of preparing yourself to give honest answers under difficult questioning, and describe courses for avoiding legalistic traps.

The purpose of this book review/editorial is to draw the profession's attention to one of the few books available on the subject, and to emphasize the crucial nature of depositions. It is hoped that this book, and others like it, will serve as worthy aids in the defense of professional liability cases.

GEORGE W. NORTHUP, D.O., FAAO

\section{editorial comment}

Breast cancer now occurs in 1 of 10 women. In $1987,130,000$ women were stricken. In an attempt to drastically reduce these numbers, the American Cancer Society (ACS) has launched the Breast Can- cer Detection Awareness Program. In conjunction with ACS's Cancer Control Month, volunteers distributed the leaflet "Now, breast cancer has virtually no place to hide." The ACS hopes to reach millions of women through the long-range program, which began in April.

For early detection of breast cancer, the following guidelines are recommended: Monthly breast selfexamination for women 20 and over; regular clinical breast examinations performed by a physician; and mammography every year for asymptomatic women 50 and over, every 1-2 years for women 40-49, and a baseline mammogram for women 35-39.

By enlisting the cooperation of the medical profession in this intensive, long-term effort, the ACS hopes to change the attitudes and habits of women regarding breast examination and mammography. New material for physicians includes the following: "Breast cancer awareness," a question and answer pamphlet; "One picture saves a thousand lives," a general information piece on mammography; and "Breast cancer detection," a program manual. Some expected outgrowths of the program include reducing the cost of mammography by increasing volume demand, and securing the support of thirdparty health insurance companies in underwriting the costs for asymptomatic women.

\section{Control of blood pressure without medication} may be possible for some patients if they manage to lose weight and reduce their intake of sodium and alcohol.

These findings were reported in the March 20, 1987, issue of The Journal of the American Medical Association. Rose Stamler, M.A., and colleagues at Northwestern University Medical School in Chicago conducted a 4-year nutrition study of 189 patients. The patients were divided into 3 groups: group 1, who discontinued drug therapy and reduced overweight, excess salt, and alcohol; group 2, who discontinued drug therapy with no nutritional program; and group 3, who continued drug therapy but had no nutritional program. Results showed that at 4 years, 39 percent of those in group 1 remained normotensive without medication. In group 2 , only 5 percent were observed to have this same result. Among the group 1 patients, those most likely to control their blood pressure with diet alone had the mildest form of hypertension before entering the program and were also less likely to be overweight.

A second study by Dannenberg and Kannel in the same issue of JAMA shows that while there may be a small group of patients who can remain 
normotensive without medication, most will relapse and require medical control of blood pressure at a later time.

An adhesive skin patch to soothe the pain of dying cancer patients is an idea being explored by University of Michigan pharmacy researcher Gordon Flynn.

Professor Flynn is pursuing a strategy that, if successful, will allow terminal cancer patients and others suffering from pain associated with disease or trauma to be alert, mobile, and free of pain with little or no side effects, and without the use of pills or injections. He proposes placing a narcotic inside an adhesive patch, about the size of a half dollar. The drug would be absorbed into the bloodstream at a steady enough rate to dull the pain, but not the senses.

As physicians know, drug patches have been used for a number of years to provide a steady supply of nitroglycerin to ward off chest pain in angina patients and to prevent motion sickness in travelers. This is among the first attempts to adapt that technology to narcotic analgesics.

Is there really a biologic basis for mental illness? This theory goes back to the beginnings of medicine. The ancient Greeks, for instance, referred to depression as melan-cholia, or a disease due to an excess of "black bile." Today, a lot of evidence suggests that the Greeks may have been on the right track.

The genetic nature of some mental disorders supports the idea that there is a biologic basis to mental illness. But a strong case can also exist for the effect of some environmental factors on mental illness. This "nature versus nurture debate" was addressed at a recent 2-day symposium sponsored by the National Institute of Mental Health (NIMH). Even though the participants arrived at only one conclusion-there is no simple answer-a major highlight of the meeting demonstrated the growing awareness of a biologic basis for certain major mental illnesses and behavioral disorders, which in the past had been regarded as learned or environmentally caused aberrations.

Anxiety, depression, schizophrenia, Alzheimer's disease, alcohol and drug abuse, and even suicide were discussed. According to a number of papers, there appears to be an imbalance of such neurotransmitters as norepinephrine and serotonin in the brains of patients who commit or attempt to commit suicide.

There is no question that the identification of biologic components for mental illness could be of inestimable value to clinicians in the diagnosis, treatment, and possible prevention of such disorders.

Undertreatment of pain is a serious problem that needs to be addressed. According to a consensus statement issued by a National Institutes of Health panel, millions of Americans who are suffering from acute pain after surgery or from cancer-associated pain are receiving doses of analgesics that are too low or too infrequent to be effective.

In response to the NIH statement, Du Pont Pharmaceuticals sponsored a symposium on February 25,1987 , which was aimed at emphasizing the importance of communication in the treatment of pain and at addressing misconceptions about analgesics and the fear that their use will lead to addiction. In a step toward improved communication, the company announced the publication of a booklet, "How to talk to your doctor about acute pain," which is available to patients and health care professionals.

Because pain is subjective, its clinical assessment depends heavily on physician-patient communication. According to the NIH statement, communication is the single most useful method for evaluating acute pain.

The nursing home population has been growing and likely will continue to grow with the increase in numbers of elderly. Currently, 1 million people reside in nursing homes in the United States, and over two-thirds of these are women. While only 5 percent of the elderly population is in a nursing home at any one time, approximately 20 to 30 percent of all people can expect to spend some time in a nursing home setting, according to the National Institute on Aging.

Despite the fact that today's nursing homes are greatly improved and more accommodating to the needs of individuals than in the past, most people still prefer to remain in their own homes as long as possible. A number of alternatives are available in most communities that can help older people to remain independent or to be cared for at home by their families. Community services may include: homemaker or home health aide services; homedelivered meals; transportation and escort services; choreworkers; a Friendly Visitors Program; adult day programs that provide social and/or health care services; respite care, which provides temporary relief for caregivers; and emergency medical systems. When home care and community services are no longer adequate, a person must continued on page $351 / 70$ 


\section{When a type ll diabetic patient needs more than diet, unique MICRONASE ${ }^{\circledR}$ Tablets (glyburide) are a logical first choice.}
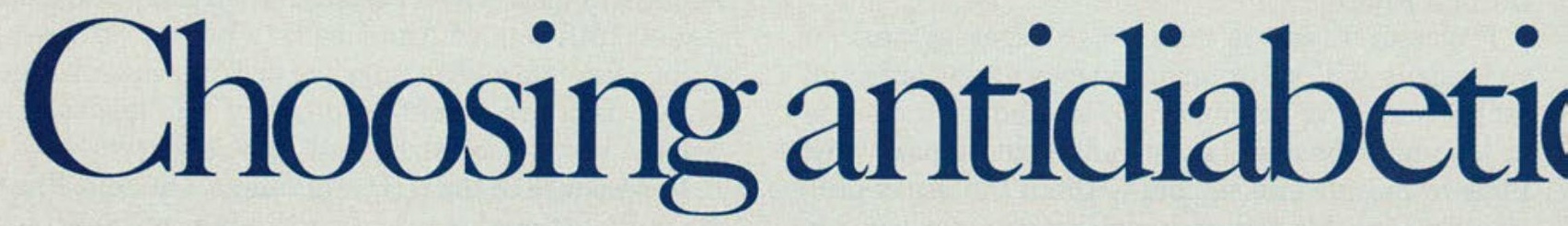

1. Micronase-a rational choice in type II diabetes Insulin levels are normal or elevated in most patients with type II diabetes, although insulin action is markedly impaired. MICRONASE helps normalize the tissue response to endogenous insulin.

Initially, MiCRONASE helps lower serum glucose in responsive patients by stimulating the release of additional insulin. As therapy continues, MicronASE is believed to promote peripheral glucose metabolism by helping to correct defects at the cellular receptor and postreceptor levels.

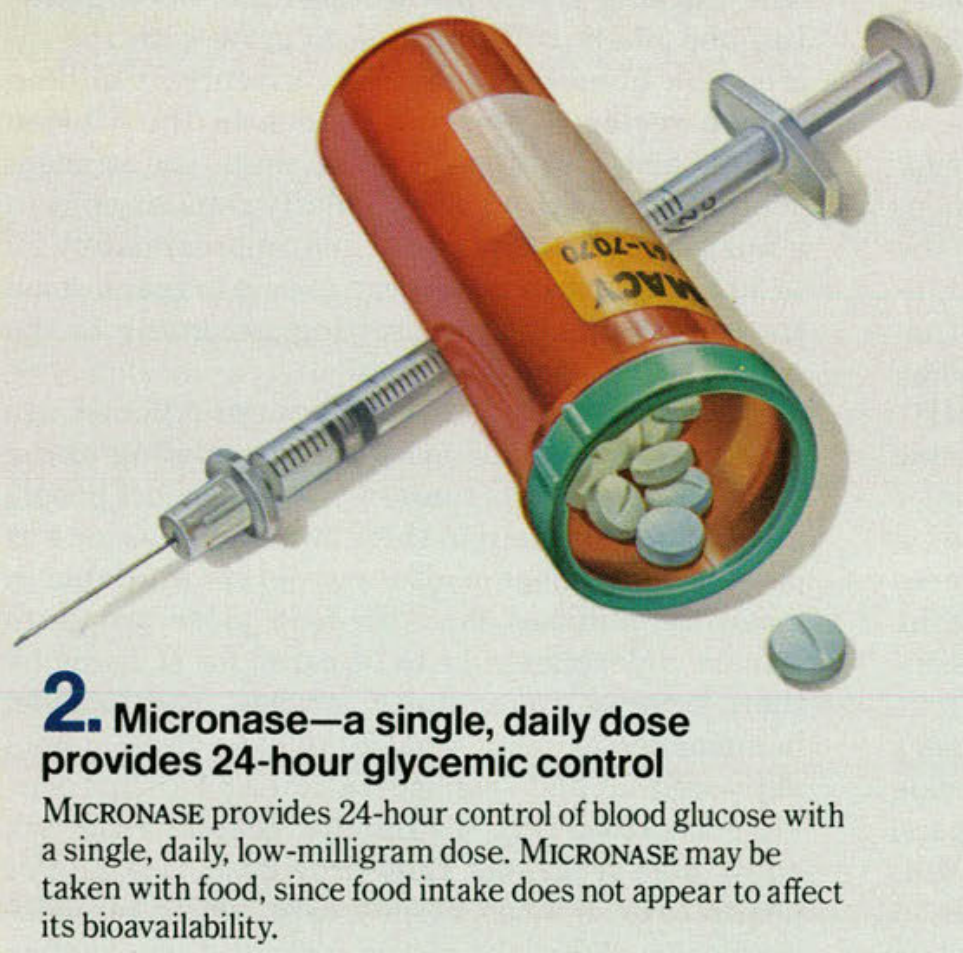

3. Micronase-for the type II diabetic patient who is also hypertensive: Control without risk of water retention

This may also be significant for the type II diabetic pat with congestive heart failure. MiCRONASE actually cau: mild diuresis. 


\section{herapy today}

- Micronase-an important consideration in e type II diabetic patient with renal impairent: Control plus unique dual excretion... $\%$ urine, $50 \%$ bile

mination of MiCRONASE equally in bile and urine reduces the $\mathrm{k}$ of drug accumulation, which may result in hypoglycemia. CRONASE should be used with caution in patients with renal pairment; however, in a single-dose study, plasma clearance of CRONASE was prolonged only in patients with severe renal pairment.
5. Micronase-for the patient who fails on other diabetic therapy: Potency and dosage flexibility

MíCRONASE may prove effective when other drugs fail. Five mg of MICRONASE is approximately equivalent to $250 \mathrm{mg}$ of chlorpropamide or $500 \mathrm{mg}$ of acetohexamide in its ability to lower blood glucose. The dosage range of MiCRONASE allows for greater dosage flexibility than other agents.

Overdosage of sulfonylureas, including MiCRONASE, can cause hypoglycemia. Although the interpretations are controversial, the UGDP study reported in 1970 that the use of tolbutamide, an oral hypoglycemic drug, was associated with increased cardiovascular mortality.

\section{Upjohn}

The Upjohn Company Kalamazoo, Ml 49001

\section{Your initial Rx in type ll diabetes}

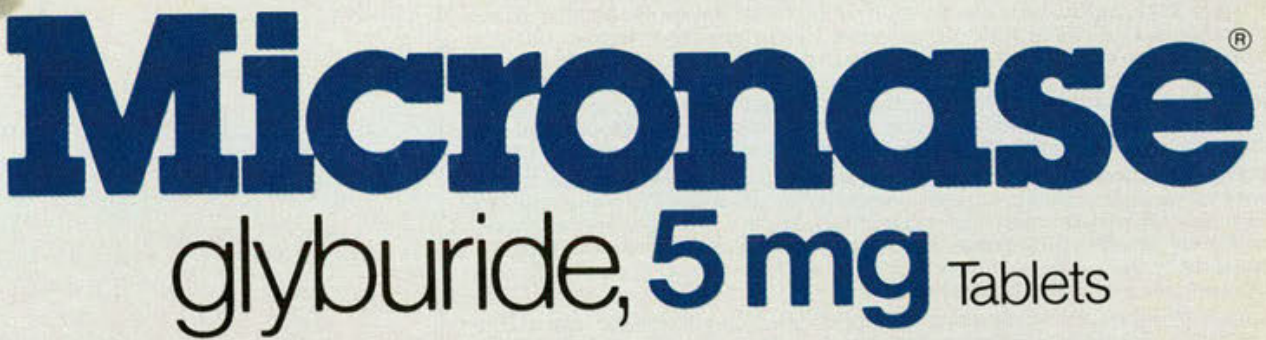


Micronase ${ }^{\circledR}$ Tablets (glyburide)

Dosage Guide:*Although relatively rare, hypoglycemia may occur during the conversion to MICRONASE from other therapy.

\begin{tabular}{lll}
$\begin{array}{l}\text { Prior therapy } \\
\text { or condition }\end{array}$ & $\begin{array}{l}\text { Considerations before } \\
\text { starting therapy }\end{array}$ & $\begin{array}{l}\text { Initial MICRONASE } \\
\text { dose (mg/day) }\end{array}$ \\
\hline Dietary therapy ineffective & No priming necessary & 1.25 to $5 \mathrm{mg}$ \\
\hline Oral therapy & Discontinue oral hypoglycemict & 2.5 to $5 \mathrm{mg}$ \\
\hline $\begin{array}{l}\text { Insulin therapy } \\
\text { (<40 units/day) }\end{array}$ & $\begin{array}{l}\text { Completely discontinue insulin injections } \\
\text { under medical supervision }\end{array}$ & 2.5 to $5 \mathrm{mg}$ \\
\hline $\begin{array}{l}\text { Insulin therapy } \\
\text { ( }>40 \text { units/day) }\end{array}$ & $\begin{array}{l}\text { Gradually discontinue insulin injections under } \\
\text { close medical observation or hospitalization }\end{array}$ & $5 \mathrm{mg}$ \\
\hline
\end{tabular}

* See complete prescribing information.

†See package insert for special precautions when transferring patients from chlorpropamide

Micronase Tablets (brand of glyburide tablets)

CONTRAINDICATIONS: MICRONASE Tablets are contraindicated in patients with: 1. Known hypersensitivity or allergy to the drug. 2. Diabetic ketoacidosis, with or without coma. This condition should be treated with insulin. 3 . Type I diabetes mellitus, as sole therapy.

SPECIAL WARNING ON INCREASED RISK OF CARDIOVASCULAR MORTALITY: The administration of oral hypoglycemic drugs has been reported to be associated with increased cardiovascular mortality as compared to treatment with diet alone or diet plus insulin. This warning is based on the study conducted by the University Group Diabetes Program (UGDP), a long-term prospective clinical trial designed to evaluate the effectiveness of glucose-lowering drugs in preventing or delaying vascular complications in patients with noninsulin-dependent diabetes. The study in volved 823 patients who were randomly assigned to one of four treatment groups (Diabetes, 19 [Suppl 2]: 747-830, 1970).

UGDP reported that patients treated for 5 to 8 years with diet plus a fixed dose of tolbutamide (1.5 grams per day) had a rate of cardiovascular mortality approximately 2-1/2 times that of patients grams per day) had a rate of cardiovascular mortality approximately 2-1/2 times that of patients treated with diet alone. A significant increase in total mortality was not observed, but the use olbutamide was discontinued based on the increase in cardiovascular mortality, thus limiting the opportunity for the study to show an increase in overall mortality. Despite controversy regarding the interpretation of these results, the findings of the UGDP study provide an adequate basis for this warning. The patient should be informed of the potential risks and advantages of MICRONASE and of alternative modes of therapy.

Although only one drug in the sulfonylurea class (tolbutamide) was included in this study, it is prudent from a safety standpoint to consider that this warning may apply to other oral hypoglycemic drugs in this class, in view of their close similarities in mode of action and chemical structure.

PRECAUTIONS: General - Hypoglycemia: All sulfonylureas are capable of producing severe hypoglycemia. Proper patient selection and dosage and instructions are important to avoid hypoglycemic episodes. Renal or hepatic insufficiency may increase the risk of serious hypoglycemic reactions. Elderly, debilitated or malnourished patients, and those with adrenal or pituitary insufficiency, are particularly susceptible to the hypoglycemic action of glucoselowering drugs. Hypoglycemia may be difficult to recognize in the elderly and in people who are than one glucose-lowering drug is used loss of Control of Blood Glucose: In diabetic patients exposed to stress such as fever, trauma, infection or surgery, a loss of control may occur. It may then be necessary to discontinue MICRONASE and administer insulin. Adequate adjustment of dose and adherence to diet should be assessed before classifying a patient as a secondary failure. Information for Patients: Patients should be informed of the potential risks and advan tages of MICRONASE and of alternative modes of therapy. They also should be informed about the importance of adherence to dietary instructions, of a regular exercise program, and of regular testing of urine and/or blood glucose. The risks of hypoglycemia, its symptoms and treatment, and conditions that predispose to its development should be explained to patients and responsible family members. Primary and secondary failure should also be explained.

Laboratory Tests: Response to MICRONASE Tablets should be monitored by frequent urine glucose tests and periodic blood glucose tests. Measurement of glycosylated hemoglobin levels may be helpful in some patients. Drug Interactions: The hypoglycemic action of sulfonylureas may be
potentiated by certain drugs including nonsteroidal anti-inflammatory agents and other drugs that are highly protein bound, salicylates, sulfonamides, chloramphenicol, probenecid, coumarins, monoamine oxidase inhibitors, and beta adrenergic blocking agents. Certain drugs tend to produce hyperglycemia and may lead to loss of control. These drugs include the thiazides and other diuretics, corticosteroids, phenothiazines, thyroid products, estrogens, oral contraceptives, phenytoin, nicotinic acid, sympathomimetics, calcium channel blocking drugs, and isoniazid. A potential interaction between oral miconazole and oral hypoglycemic agents leading to severe hypoglycemia has been reported. Carcinogenesis, Mutagenesis, and impairment of Fertility. Studies in rats at doses up to

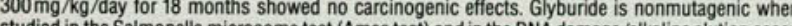
studied the Salmonella microsome test (Ames test) and in the DNA damage/alkaline elution assay. Pregnan. Teratogenic Effects: Pregnancy Category B. Reproduction studies in rats and rabbits have revealed no evidence of impaired fertility or harm to the fetus due to glyburide. There are no adequate and well controlled studies in pregnant women. This drug should be used during pregnancy only if clearly needed. Insulin should be used during pregnancy to maintain blood glucose as close to normal as possible. Nonteratogenic Effects: Prolonged severe hypoglycemia (4 to 10 days) has been reported in neonates born to mothers who were receiving a sulfonylurea drug at the time of delivery. MICRONASE should be discontinued at least two weeks before the expected delivery date Nursing Mothers: Some sulfonylurea drugs are known to be excreted in human milk. Insulin therapy should be considered. Pediatric Use: Safety and effectiveness in children have not been established

ADVERSE REACTIONS: Hypoglycemia: See Precautions and Overdosage sections. Gastrointestinal Reactions: Cholestatic jaundice may occur rarely; MICRONASE Tablets should be discontinued if this occurs. Gastrointestinal disturbances, e.g. nausea, epigastric fullness, and heartburn, are the most common reactions, having occurred in $1.8 \%$ of treated patients during clinical trials. They tend to be dose-related and may disappear when dosage is reduced. Liver function abnormalities, including isolated transaminase elevations, have been reported. Dermatologic Reactions: Allergic skin reactions, e.g., pruritis, erythema, urticaria, and morbilliform or maculopapular eruptions, occurred in $1.5 \%$ of treated patients during clinical trials. These may be transient and may disappear despite continued use of MICRONASE; if skin reactions persist, the drug should be discontinued Porphyria cutanea tarda and photosensitivity reactions have been reported with sulfony Reactions: Leukopenia, agranulocytosis, thrombocytopenia, hemolytic anemia, aplastic anemia, and disulfiram-like reactions have been reported with sulfonylureas; however, hepatic porphyria has and disulfiram-like reactions have been reported with sulfonylureas; however, hepatic porphyria has
not been reported with MICRONASE and disulfiram-like reactions have been reported very rarely. OVERDOSAGE: Overdosage of sulfonylureas, including MICRONASE Tablets, can produce hypoglycemia. If hypoglycemic coma is diagnosed or suspected, the patient should be given a rapid intravenous injection of concentrated $(50 \%)$ glucose solution. This should be followed by a continuous infusion of a more dilute $(10 \%)$ olucose solution at a rate which will maintain the blood glucose at level above $100 \mathrm{mg} / \mathrm{dL}$. Patients should be closely monitored for a minimum of 24 to 48 hours, since hypoglycemia may recur after apparent clinical recovery.

Caution: Federal law prohibits dispensing without prescription. Store at controlled room temperature $15^{\circ}-30^{\circ} \mathrm{C}\left(59^{\circ}-86^{\circ} \mathrm{F}\right)$. Dispensed in well closed containers with safety closures. Keep container tightly closed.

For additional product information see your Upjohn representative.

Upiohn THE UPJOHN COMPANY

Kalamazoo, MI 49001, USA

decide on the best alternative arrangement for meeting long-term personal and health care needs.

The National Institute on Aging supplies information on long-term care options and publishes fact sheets on related topics of interest to older people and their families. For a complete listing of publications distributed by the National Institute on Aging, call or write to NIA Information Center, 2209 Distribution Circle, Silver Spring, MD 20910, (301) 495-3455. Single copies of the publications are available free of charge.

The overall death rate from cancer is decreasing among the U.S. population younger than age 55 , according to a report by the National Cancer Institute. "This decline in the death rate comes in the face of a slow increase in the cancer incidence rate in this age group, and is one of the most encouraging cancer statistics we see this year," said Vincent T. DeVita, Jr., M.D., director of the National Cancer Institute. The cancer death rate for persons younger than 55 years decreased 6.5 percent-from 38.2 per 100,000 population in 1975 to 35.7 in 1984 . It is seen even if lung cancer death rates, which are decreasing among young and middle-aged individuals, are excluded.

The decline in the death rate and the higher overall relative survival rate for patients with cancer in this age group is attributed by Dr. DeVita primarily to advances in cancer treatment. 
Proposed Amendment to the Bylaws of the American Osteopathic Association

In March, 1987, the AOA Board of Trustees, upon recommendation of the Committee on Membership, is proposing the following Amendment to the AOA Bylaws for consideration by the AOA House of Delegates at its July, 1987 meeting:

(Note: In the proposed Amendment set out below, material to be deleted appears in brackets [ ].)

\section{Article III, Section 1}

d. Resident Rate. Dues for regular members serving in residency training programs [approved by the American Osteopathic Association] shall be twenty dollars (\$20.00) per year. [A member who has submitted an application for approval of a non-osteopathic residency training program to the AOA Department of Education shall be allowed the residency rate of dues.] One fiscal year at the residency rate of dues is to be allowed for each year of residency.

\section{Official call}

To the officers and members of the American Osteopathic Association:

You are hereby notified that the annual meeting of the American Osteopathic Association will be held in Chicago, Illinois on July 23-27, 1987 at the Chicago Marriott Hotel.

The opening session of the annual meeting of the Board of Trustees will be held at 9:00 a.m. on Thursday, July 23.

The House of Delegates will convene for the annual business session of the association at 10:00 a.m. on Sunday, July 26. All meetings of the House of Delegates will be held at the Chicago Marriott Hotel. The Committee on Credentials will register delegates and alternate delegates beginning at 8:30 a.m. on Sunday, July 26. The House will conclude its session on Monday, July 27.

At least 30 days prior to the first day of the annual meeting, the secretary of each divisional society must certify to the executive director of the American Osteopathic Association a list of the names and addresses of delegates and alternate delegates.

Eugene L. Sikorski, D.O., President

T. Eugene Zachary, D.O., Speaker of the House

\section{A New Marketing Tool for Young Patients}

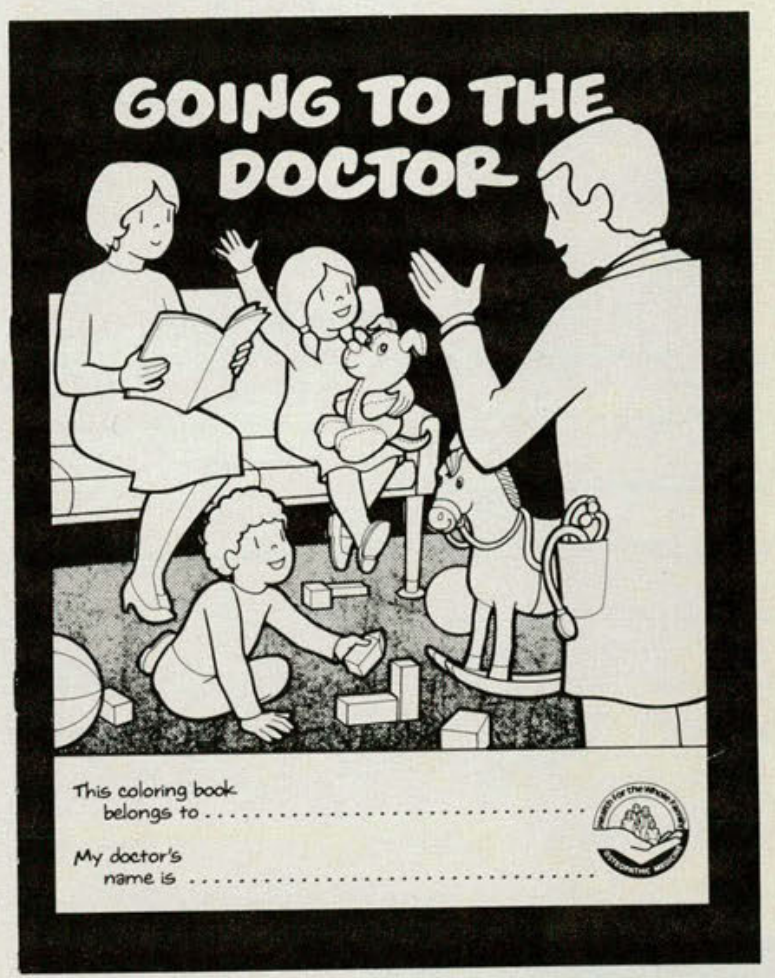

This eight page coloring book tells in simple terms what the D.O. does when giving a physical exam and presents in anxiety-allaying style some of his procedures. While waiting in the office, parents can talk it through, then take it home as a fun souvenir. Note that it can be personalized by adding your name on the cover.

Single review copies available at no charge. Additional copies $25 \varnothing$ each.

\section{Order from:}

Public Relations Department AMERICAN OSTEOPATHIC ASSOCIATION

212 East Ohio Street Chicago, IL 60611

(1-800) 621-1773 


\section{ADVANCE CONVENTION REGISTRATION FORM}

92nd Annual Convention and Scientific Seminar

American Osteopathic Association

See reverse side for instructions and further information

ORLANDO, FLORIDA

OCTOBER 4-8, 1987

NAME AND OFFICE ADDRESS (Print Clearly)

Name

AOA No.

Address

City \& State

Zip Code

Adult Guest(s)

Juvenile Guest(s)

CHECK YOUR REGISTRATION CATEGORY AND THE CATEGORY FOR YOUR GUESTS: ENCLOSE CHECK FOR FEES

MEMBER of one of the following participating affiliated organizations. CHECK ONE organization only. If you are a member of more than one group, check the ONE which you prefer to have receive exhibit income credit for your attendance.

SPECIFY ALUMNI LUNCHEON

\section{SECTION I}

American Academy of Osteopathy

Member

$\$ 175 \dagger$

Guest

American Osteopathic College of Allergy and Immunology

Member

Guest

$\$ 75 t$

American Osteopathic College of Dermatology

Member ...................... $\mathbf{\$ 1 5 0 \dagger}$

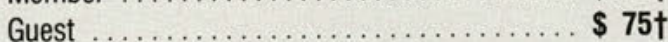

American College of Osteopathic Emergency Physicians

Member .....................\$175†

Guest ....................... $\$ \mathbf{7 5 \dagger}$

American College of General Practitioners in Osteopathic

Medicine and Surgery

$\square \quad$ Member

$\$ 175 \dagger$

Guest

$\$ 100 \dagger$

American College of Neuropsychiatrists

Member

$\$ 185 \dagger$

$\$ 110 \dagger$

Guest

$\$ 225 \dagger$

Guest ......................... $\$$

American Osteopathic College of Preventive Medicine

Member ......................\$180†

Guest ....................... $\$$

American Osteopathic College of Rehabilitation Medicine

Member .......................\$\$\$ $200 \dagger$

Guest ........................\$\$ $\$ 125 t$

American Osteopathic College of Rheumatology, Inc.

Member

$\$ 150^{*}$

Guest

75*

American Osteopathic Academy of Sclerotherapy, Inc.

Member

$\$ 180 \dagger$

$\$ 105 \dagger$

American Osteopathic Academy of Sports Medicine

Member

$\$ 175 t$

$\$ 100 \dagger$

\section{SECTION II}

American Osteopathic Association

Member ..................... $\$ \mathbf{\$ 1 5 0 *}$

Adult Guest - With AOA tickets ......... \$ 75*

Adult Guest - Without AOA tickets ..... no fee +

Juvenile Guest ................ no fee +

Intern $\ldots \ldots \ldots \ldots \ldots \ldots \ldots \ldots \ldots$ no fee +

Resident $\ldots \ldots \ldots \ldots \ldots \ldots \ldots \ldots$ no fee +

Student . . . . . . . . . . . . . . no fee +

Adult Guest of Intern, Resident or Student no fee +

Associate Member ................ $\$ \mathbf{5 0 \# ~}$

Nonmember . . ................ $\$ 425^{\star} \ddagger$

Auxiliary to the AOA

Member - With AOA tickets

$\$ 75^{*}$

Member - Without AOA tickets no fee +

\section{SECTION III}

Canadian Osteopathic Association

Member

Nonmember

\section{KEY TO SYMBOLS}

* Includes tickets, for one person, to AOA President's Dinner. In addition, D.O.'s receive College Alumni Luncheon ticket and guests receive ticket to AOA Entertainment for Spouses of D.0.'s.

† Includes tickets, for one person, to AOA President's Dinner and all social functions planned by this individual group. In addition, D.O.'s receive College Alumni Luncheon ticket and guests receive ticket to $A O A$ Entertainment for Spouses of D.0.'s.

+ Individual tickets for social functions may be purchased.

\# Includes ticket, for one person, to AOA President's Dinner.

$\ddagger$ See registration rules on reverse side.

COMPLETE the above FORM (see instructions on reverse side), ATTACH CHECK for registration fee made PAYABLE TO THE AMERICAN OSTEOPATHIC ASSOCIATION, to cover fees, and RETURN TO:

Convention Office • American Osteopathic Association • 212 E. Ohio St. • Chicago, IL 60611

Registration packets will be mailed out prior to the convention to those who register in advance. Advance registration forms must be received no later than September 1,1987 . There will be a $\$ 15.00$ late charge for registration in Orlando. Refunds on cancellations will be made if received no later than September 1, 1987. 


\section{REGISTRATION INSTRUCTIONS}

\section{THOSE WHO MAY REGISTER}

Members of the American Osteopathic Association or the Canadian Osteopathic Association, their adult guests (who are not osteopathic physicians) and their children.

Osteopathic physicians who are NOT members of the AOA may register, but are required to pay a fee of $\$ 425.00$. Osteopathic physicians, if eligible, may thereupon apply for AOA membership at the registration desk and, if they are accepted into membership, $\$ 275.00$ of the Nonmember registration fee will be applied to their annual dues. Membership in the Canadian Osteopathic Association may substitute for AOA membership if the doctor is located in Canada.

Students and students' spouses.

Commercial and scientific exhibitors.

\section{HOW TO SELECT REGISTRATION CATEGORY}

\section{D.0.'s}

Check ONLY ONE category for your registration. Participating affiliated organizations are listed under Section I of the form. The American Osteopathic Association registration under Section II and other categories are listed under Section III. Regardless of the category you check, you are entitled to attend ANY of the didactic sessions put on by ANY of the participating organizations. Although membership in a participating affiliated organization is not a requirement to register for the group, AOA membership (or if a doctor is from Canada, Canadian Osteopathic Association membership) is a requirement for registration in ANY of the D.O. registration categories, except for those who have paid the higher Non-member registration fee.

If you are a member of two of the participating affiliated organizations and wish to register for both, you may do so by paying TWO registration fees - one for each group. In such case, CME credit will be allowed for only ONE of the two groups.

\section{GUESTS:}

In addition to checking your category, check the category for all your guests (being sure to indicate the guest's name in the space provided on the form).

The D.0. registration fee does NOT include tickets for anyone other than the doctor. Guests are to be registered either by paying a fee and receiving tickets, or by NOT paying a fee and NOT receiving tickets ("Adult Guest - NO tickets" category, under Section II of the form). If the doctor's guest is to have the same tickets as the doctor, then check the guest category for the group under which the doctor is registering and pay the fee indicated. In such case, however, the D.0. fee includes a College Alumni Luncheon ticket, but the Guest fee does NOT, but may be purchased separately. In addition, the guest registration fee covers a ticket to the AOA Entertainment for Spouses of D.0.'s. Those guests who do not pay a registration fee may purchase separate tickets to meal functions.

\section{TICKETS COVERED BY REGISTRATION FEE}

The fees shown on the registration form are followed by symbols to indicate the tickets which are covered by the fees. To interpret the symbols, see "Key to Symbols," in the box below Section III of the registration form. 


\section{AMERICAN OSTEOPATHIC ASSOCIATION \\ HOTEL RESERVATION APPLICATION \\ 92nd Annual Convention and Scientific Seminar}

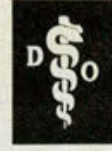

TOBER 4-8, 1987

ORLAND0, FLORIDA

\section{HOTELS REQUIRE RESERVATIONS PRIOR TO SEPTEMBER 1, 1987 - MAIL EARLY}

MAIL YOUR RESERVATION DIRECTLY TO THE AOA HOUSING BUREAU AS FOLLOWS:

A HOUSING BUREAU

ORLANDO/ORANGE COUNTY

NVENTION \& VISITORS BUREAU

30 Republic Drive, Suite 200

ando, Florida 32819

phone reservations accepted)
DO NOT make reservations directly with the hotel, but SEND this

form indicating your preference of hotel to the AOA Housing Bureau.

DICATE THREE CHOICES BY WRITING 1, 2, OR 3 IN THE APPROPRIATE BOXES (PREFERENCE BEING \#1)

EMBASSY SUITES - PLAZA INTERNATIONAL

8520 Jamaican Ct. 1-800-327-9797

Orlando, FL 32819 (305) $345-8250$

A wet bar and refrigerator in every suite. Complimentary buffet breakfast and 2 hours of complimentary cocktails served daily to all guests. Health Club, Indoor-Outdoor Pool.

Single $\$ 85$

Double $\$ 95$

\section{ORLANDO MARRIOTT}

8001 International Dr.

Orlando, FL 32819 (305) 351-2420

Rooms are located on 45 acres of tropical landscaping and

lagoons, with an all-purpose family restaurant, steak and seafood specialty restaurant, and fast food restaurant; lobby bar, 3 pools with 2 poolside bars, 4 lighted tennis courts, and a nightclub; 15 minutes from Walt Disney World, Orlando International Airport and downtown Orlando.

Single $\$ 70$

Double $\$ 70$

Suite Rates: -1 Bdrm Jr. Suite

-2 Bdrm Jr. Suite

- Hospitality Parlor

PARK SUITE

8978 International Dr.

Orlando, FL 32819 (305) 352-1400

A suite hotel overlooking a Mediterranean style atrium. Suites have a wet bar, microwave oven, and refrigerator. Gourmet dining, piano bar, indoor pool, and exercise room.

Single $\$ 85$

Double $\$ 95$

SONESTA VILLAGE HOTEL ON SAND LAKE

10000 Turkey Lake Rd.

Orlando, FL 32819 (305) 352-8051

Luxurious 1 and 2 bedroom lakefront villas featuring family size living room and fully equipped kitchen. A full service unique resort with recreational facilities including whirlpool spas, swimming, boating, tennis, and health club.

Single $\$ 95$

Double $\$ 95$

\section{SHERATON WORLD}

10100 International Dr.

Orlando, FL 32821 (305) 352-1100

Located a half mile from the Orange County Convention/Civic Center; low-rise villa design accommodations, with tropical landscaping; 3 swimming pools; 5 night-lit tennis courts; fitness center; restaurants and lounge.

Single $\$ 65$

Double $\$ 68$

Suite Rates: -1 Bdrm

$$
-2 \text { Bdrm }
$$

PEABODY ORLANDO

9801 International Dr.

Orlando, FL 32809 (305) 352-4000

A 27 story hotel, across from the Orange County Convention/Civic Center, with 6 restaurants and lounges, 4 tennis courts, swimming pool, health club, and jogging path.

Single $\$ 95$

Double $\$ 95$

Suite Rates: -1 Bdrm (no balcony) $\$ 275$

-1 Bdrm w/balcony $\quad 325$

-2 Bdrm w/balcony

STOUFFER (formerly The Wyndham)

6677 Sea Harbor Dr.

Orlando, FL 32821 (305) 351-5555

A resort hotel, located one mile from the Orange County Convention/Civic Center and directly across from Sea World and 10 minutes from Orlando International Airport. Facilities include 24-hour food service, 4 restaurants including a French gourmet and Chinese gourmet, bi-level lobby bar, and night club. Single $\$ 105$

Double $\$ 105$

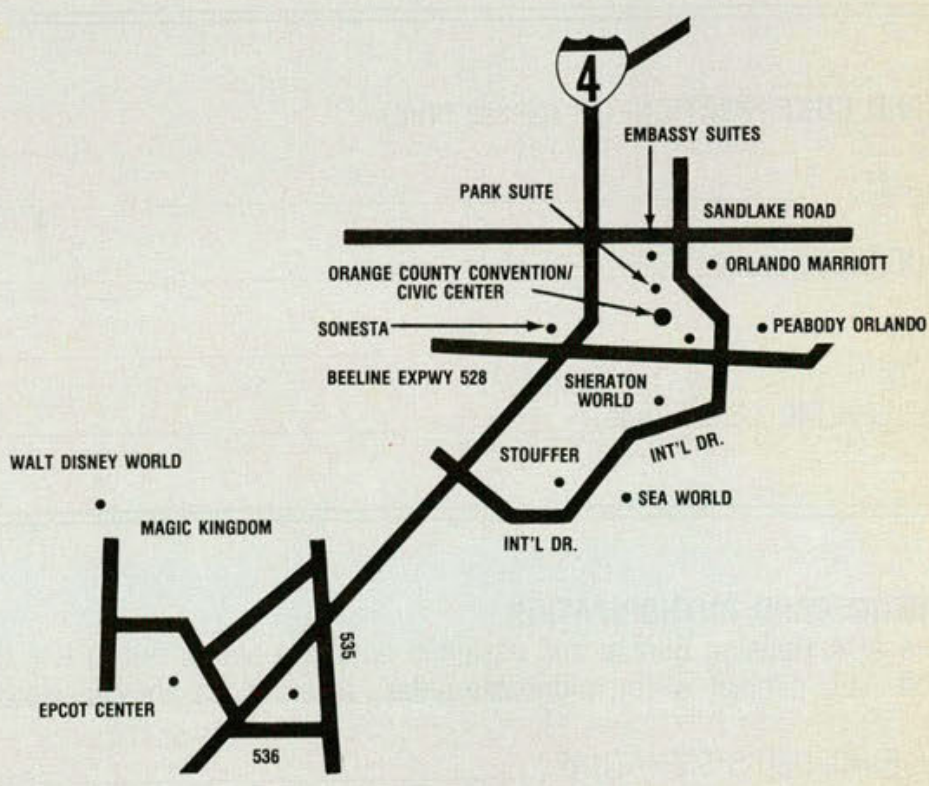




\section{IMPORTANT INFORMATION}

Please complete this form in detail. Incomplete forms will delay room assignments. All reservations will be processed on a first-cor first-served basis and must be received by the AOA Housing Bureau by September 1, 1987. Do NOT send your reservations to the hotel or American Osteopathic Association's Central Office. MAIL DIRECTLY TO THE AOA HOUSING BUREAU (address above). OnE night's deposit is required to guarantee accommodations at the hotels after confirmation is received from the hotel selected. DO NC mail checks or cash deposits with this form. Wait until you receive a confirmation from the Housing Bureau and then send your deposit directly to the hotel within 14 days of receiving confirmation from the Housing Bureau. Check out time is 12:00 Noon, (Sheraton is 11:00 a.m.); rooms may not be available until 3:00 p.m. Requests for housing must be made on the official housing form. Cancellations should be made in writing to the Housing Bureau up to 30 days prior to the meeting date. Within the last 30 days, cancellations will be accepted by phone, also by the Bureau. Date and name changes should be made directly with the hotels and not the Housing Bureau. Registration, exhibits, and didactic sessions will be held at the Orange County Convention/Civic Center The AOA will also be utilizing the following hotels for other functions as well as housing: The Embassy Suites, Orlando Marriott, Pa Suite, Peabody, Sheraton World, Sonesta, and the Stouffer (formerly The Wyndham) hotels.

Participating Groups are as follows:

American Academy of Osteopathy

American Osteopathic College of Allergy and Immunology

American Osteopathic College of Dermatology

American Osteopathic College of Pathologists

American Osteopathic College of Preventive Medicine

American Osteopathic College of Rehabilitation Medicine

American College of Osteopathic Emergency Physicians

American College of General Practitioners in Osteopathic Medicine

and Surgery

American College of Neuropsychiatrists

American Osteopathic College of Rheumatology, Inc.

American Osteopathic Academy of Sclerotherapy, Inc.

American Osteopathic Academy of Sports Medicine

Auxiliary to the American Osteopathic Association

(The Association of Osteopathic State Executive Directors and the American Association of Colleges of Osteopathic Medicine are alse meeting in conjunction with the AOA convention.)

HOTEL CHOICES: (1)

(2)

(3)

TYPE OF ACCOMMODATION: (please check one)

SINGLE $\square \quad$ DOUBLE $\square$ ROLLAWAY $\square$

SUITES: 1 BDRM $\square \quad$ 2BDRM

OTHER:

ARRIVAL DATE:

DEPARTURE DATE:
NAME OF ALL OCCUPANTS OF ROOM(S): (please print)

1.

2.

3.

APPROX. TIME

$\mathrm{AM} / \mathrm{F}$

APPROX. TIME

SEND CONFIRMATION TO: (please print)

NAME:

ADDRESS:

CITY:

STATE:

ZIP:

TELEPHONE (Area Code):

\section{CREDIT CARD AUTHORIZATION}

The AOA Housing Bureau and assigned hotel are authorized to use this information to assess a deposit for my hotel room reservation. This deposit is not refundable unless reservations are canceled 72 hours prior to arrival. 


\section{more than...}

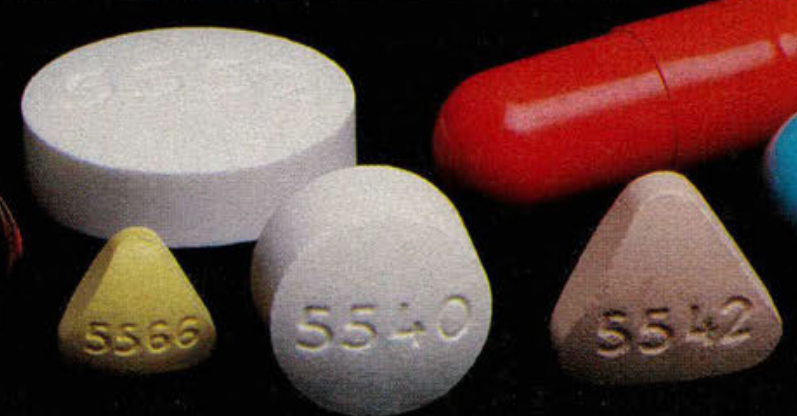

000 PHARMACEUTICAL PRODUCTS IN EVERY THERAPEUTIC CATEGORY

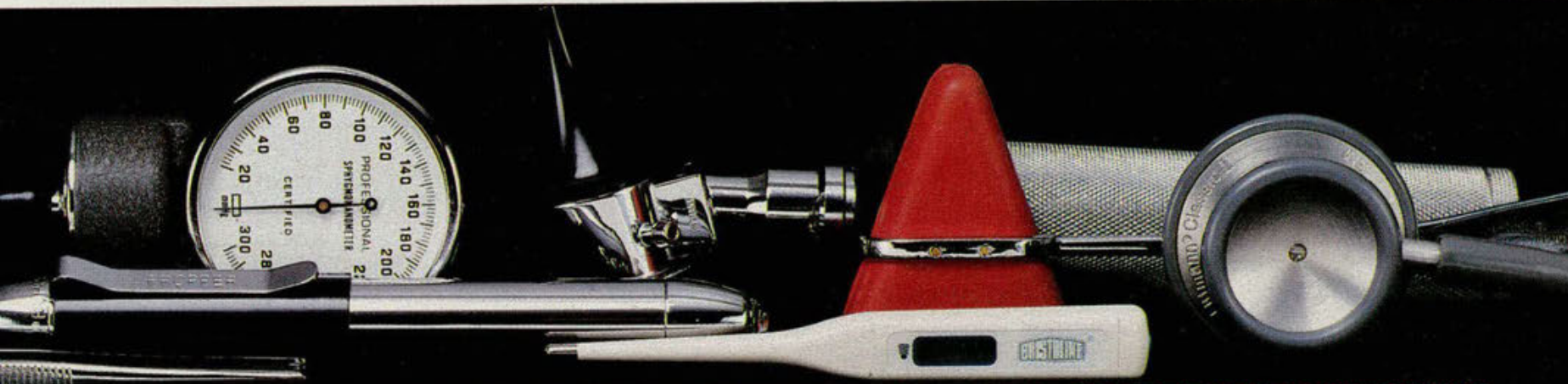

nore than...EVERY MAJOR BRAND OF DIAGNOSTIC INSTRUMENTS AT COMPETITIVE LOW PRICES

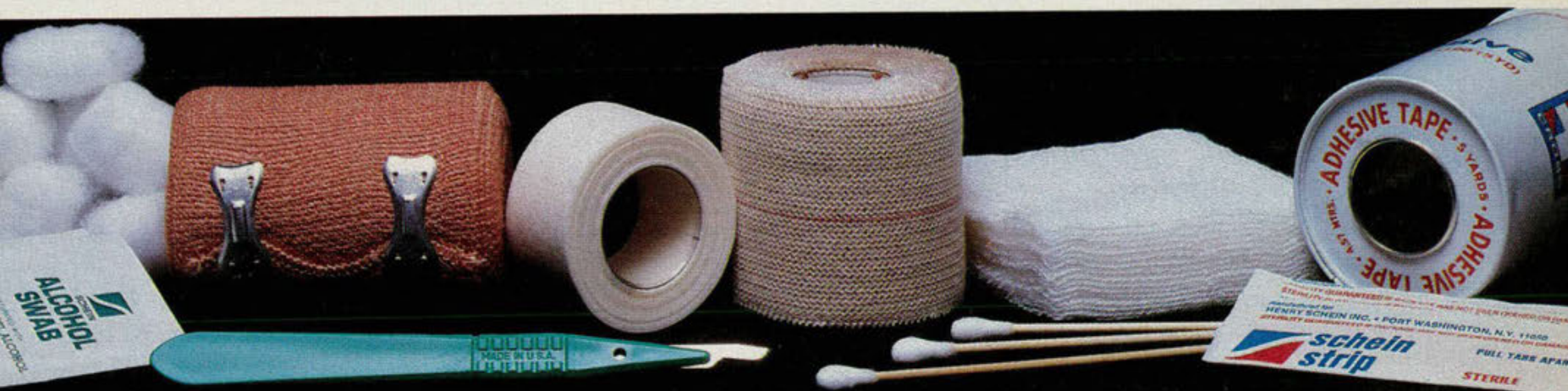

more than...HUNDREDS OF SURGICAL PRODUCTS FROM AMERICA'S FAVORITE MANUFACTURERS

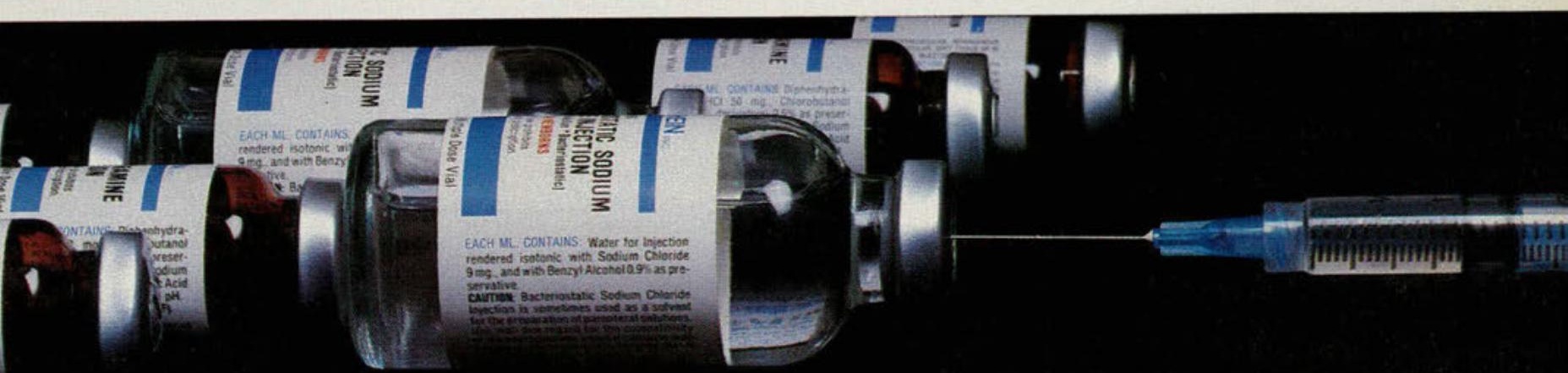

more than...500 QUALITY INJECTABLES AND SYRINGES FOR EVERY PRACTICE NEED

\section{We're all of the above and much more. WE'RE HENRY SCHEIN INC.}

The Professional's Choice for Healthcare Office Needs.

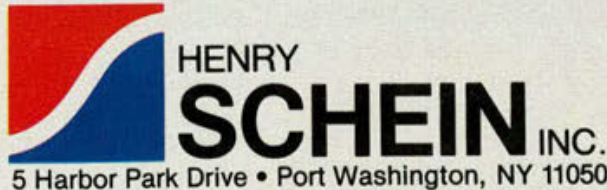

5 Harbor Park Drive $\bullet$ Port Washington, NY 11050

For a free Schein Catalog call 1-800-P-SCHEIN 


\section{American Osteopathic Association \\ Continuing Medical Education}

\section{CERTIFICATION OF HOME STUDY}

This is to certify that $\mathrm{I}$,

activity for AOA CME credits.

Please print

completed the followin

Type of activity (such as reading or listening)

Name of journal(s) or audio-tape and date(s) of issue(s):

(One-half CREDIT may be granted for each issue or tape)

AOA number

D.O.'s signature

College and year of graduation

Current address (including zip code)

MAIL TO: AOA Division of CME, 212 East Ohio Street, Chicago, Illinois 60611

\section{KEEP A DUPLICATE FOR YOUR RECORDS!}

The Home Study form is intended to document individual reading of recognized scientific journals, listening to approved audio-tapes, and other approved home study courses and programs under the criteria described for Category 2-B.

Only one type of home study, such as reading, should be indicated on a single form, though multiple issues of scientific journals may be listed.

This form should not be used, however, when CME quiz cards for the AOA Journal are submitted separately.

\begin{tabular}{|l|}
\hline FOR OFFICE USE ONLY \\
\hline Cat. $\_$Credits_-B \\
Program \# \\
Doctor \# \\
Doctor's Name \\
\hline
\end{tabular}

Please refer to the revised CME GUIDE for additional information. 


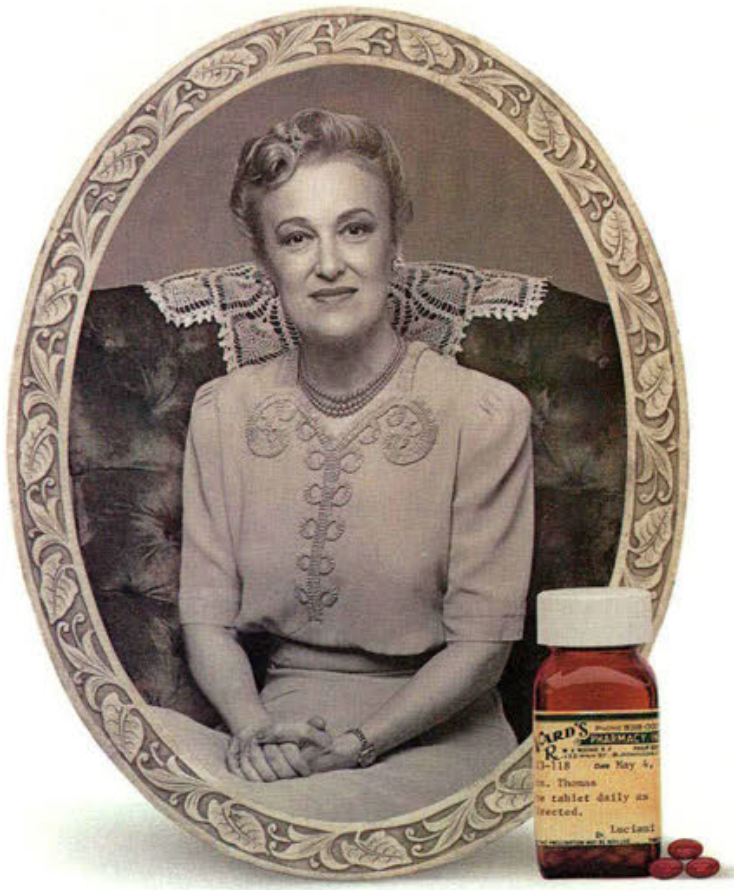

Now
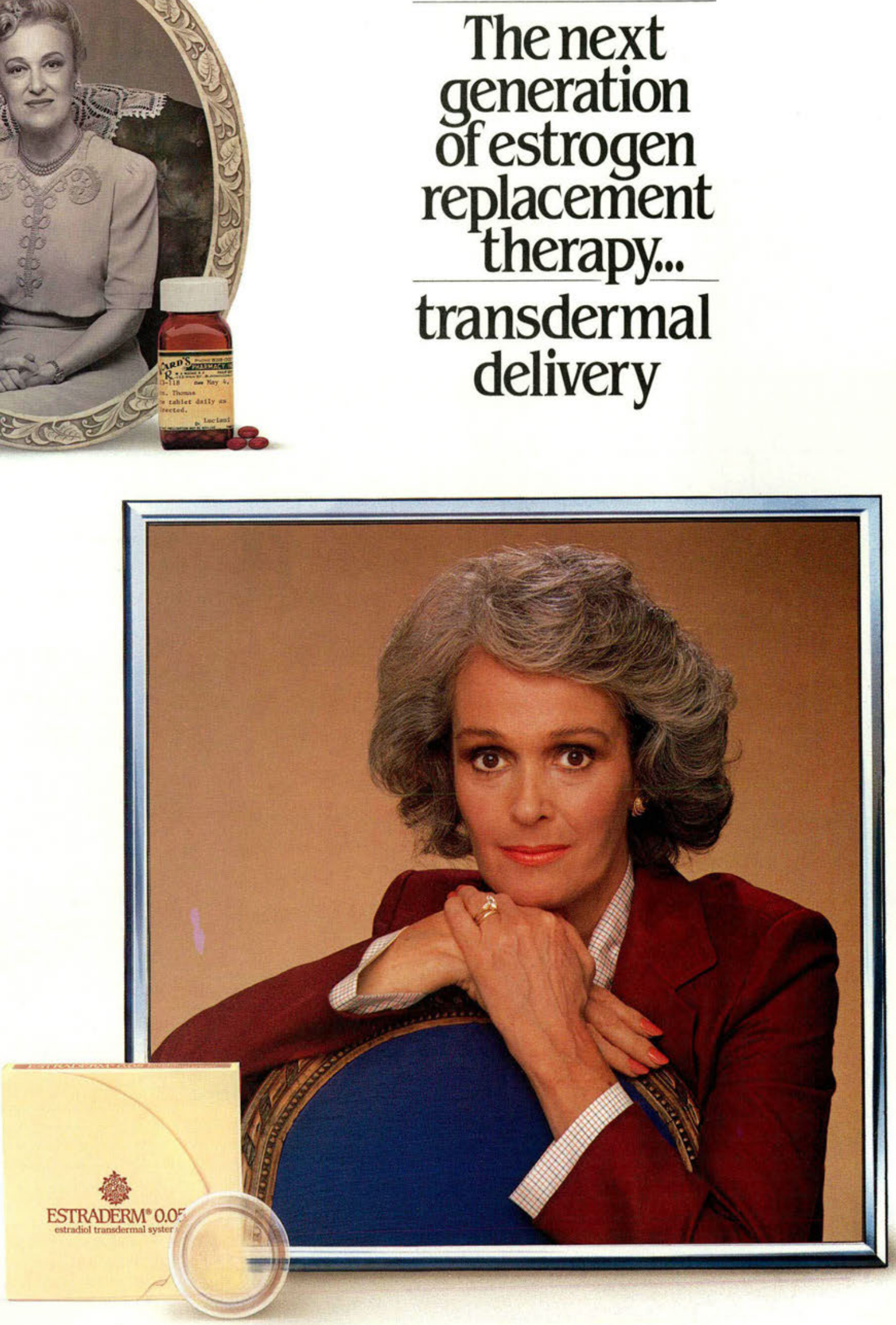


\section{NEW ESTRADERY estradiol transdermal systen}

\section{Combines the advantages of transdermal delivery...}

A specially designed

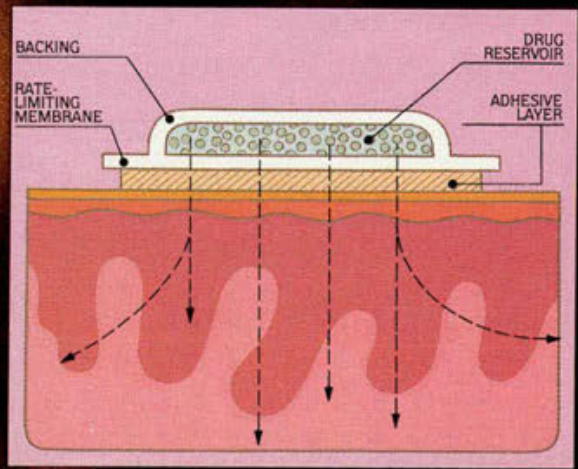
transdermal delivery system

Providing the natural ovarian estroge (17-beta estradiol) directly to the bloodstream and target organs; with no first-pass liver metabolism, permit use of extremely low dosage

Effectively controls estrogen deficiency symptoms

Steady-state relief of hot flashes, othe menopausal symptoms associated wit hot flashes, and vaginal discomfort

Well tolerated

Very low incidence of systemic side effects...few local problems of consequence

Easy to use; transdermal delivery preferred 3:1 by patients over tablets $^{1}$

Usual starting dose: a 0.05-mg system changed twice weekly 


\section{C $\quad$ I $\quad$ B $A$}

\section{ith the benefits of strogen replacement}

\section{tores and maintains premenopausal radiol serum levels}

ores estradiol levels to near-normal premenopausal ranges ieves a physiologic $1: 1$ ratio of estradiol to estrone
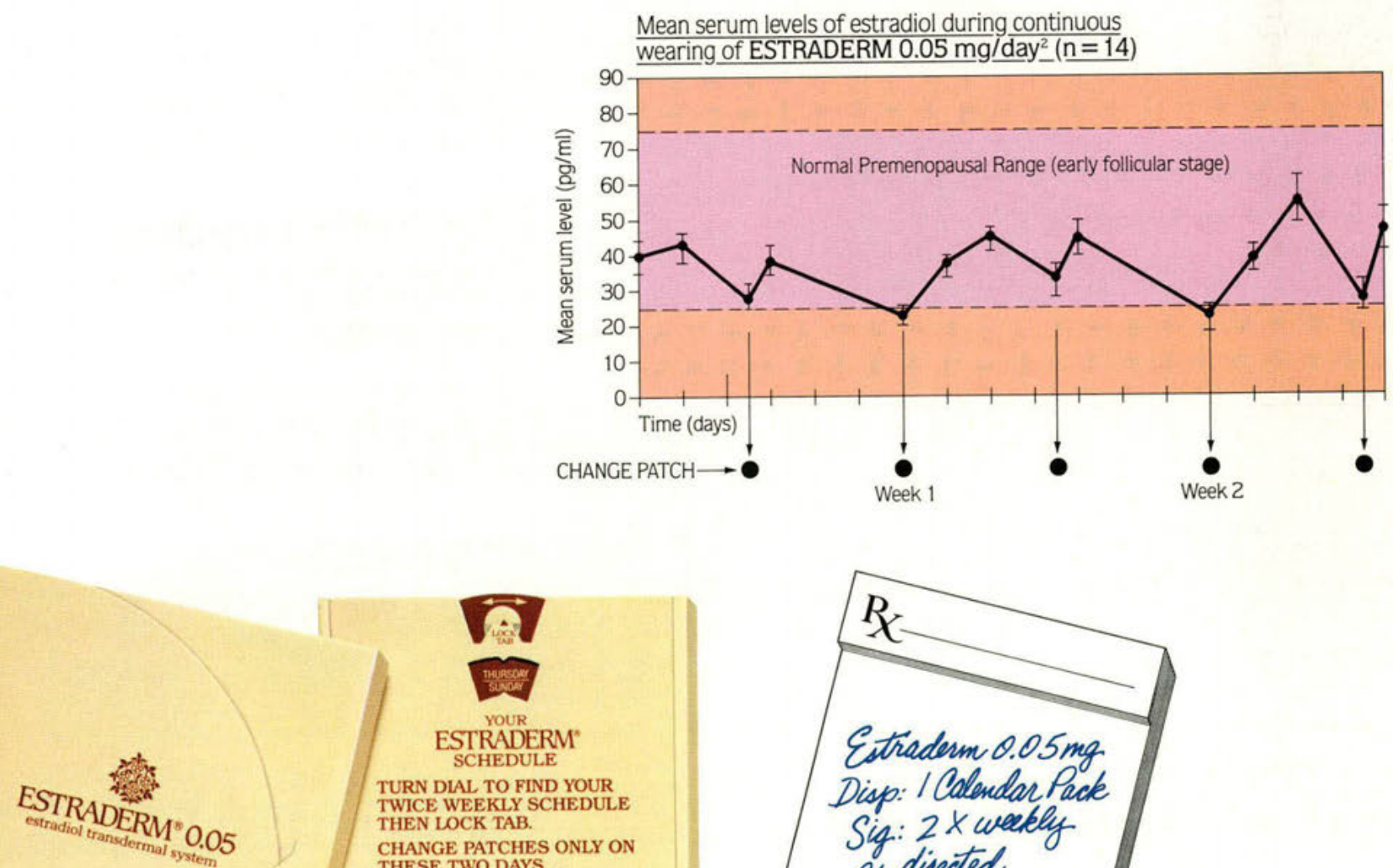

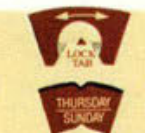

YouR

ESTRADERM

SCHEDULE

TURN DIAL TO FIND YOUR

TWICE WEEKLY SCHEDULE THEN LOCK TAB.

CHANGE PATCHES ONLY ON

THESE TWO DAYS

DO NOT CHANGE DIAL

ONCE SCHEDULE IS SET able in dose-reminder calendar packs of eight es $-0.05 \mathrm{mg} / 0.1 \mathrm{mg}$

\section{B A}

ng today's women live healthier lives

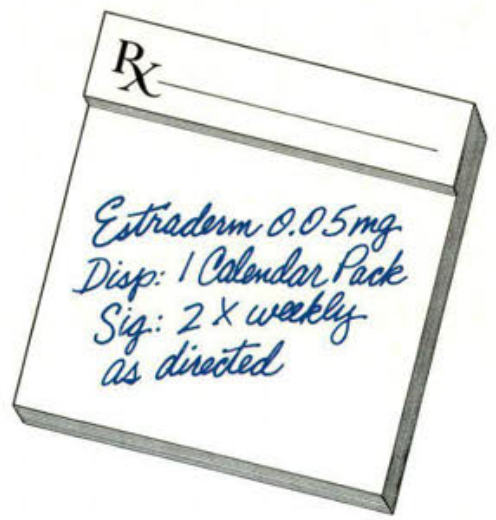

References:

1. Data on file. CIBA Pharmaceutical Company

2. Powers MS, et al: Pharmacokinetics and pharmacodynamics of transdermal dosage forms of $17 \beta$-estradiol: Comparison with conventional oral estrogens used for hormone replacement. Am J Obstet Gynecol 1985; 152:1099-1106.

Please see next page

for Brief Summary of Prescribing Information. 


\section{ESTRADERM estradiol transdermal system}

Continuous delivery for twice-weekly application.
BRIEF SUMMARY OF PRESCRIBING INFORMATION.

PLEASE SEE FULL PRESCRIBING INFORMATION.

\section{ESTROGENS HAVE BEEN REPORTED TO INCREASE THE RISK OF ENDOMETRIAL}

Three independent case control studies have reported an increased risk of endometrial cancer in postmenopausal women exposed to exogenous estrogens for more than 1 year. This risk was supported by the finding that incidence rates of endometrial cancer have increased sharply since 1969 in eight different areas of the United States with population-based cancer-reporting systems, an increase which may be related to the rapidly expanding use of estrogens during the last decade. The three case control studies reported that the risk of endometrial cancer in estrogen users was about 4.5-13.9 times greater than in nonusers. The risk appears to depend both on duration of treatment and on estrogen dose. In view of these findings, when estrogens are used for the treatment of menopausal symptoms, the lowest dose that will control symptoms should be utilized and medication should be discontinued as soon as possible. When prolonged treatment is medically indicated, the patient should be reassessed on at least a semiannual basis to determine the need for continued therapy. Although the evidence must be considered preliminary. one study suggests that cyclic administration of low doses of estrogen may carry less risk than continuous administration; it therefore appears prudent to utilize such a regimen.

Close clinical surveillance of all women taking estrogens is important. In all cases of undiagnosed persistent or recurring abnormal vaginal bleeding, adequate diagnostic measures should be underken to rule out malignancy.

There is no evidence at present that "natural" estrogens are more or less hazardous than

\section{ESTROGENS SHOULD NOT BE USED DURING PREGNANCY.}

The use of female sex hormones, both estrogens and progestogens, during early pregnancy may seriously damage the offspring. It has been shown that women who had been exposed in utero to diethylstilbestrol, a nonsteroidal estrogen, have an increased risk of developing in later life a form of vaginal or cervical cancer that is ordinarily extremely rare. This risk has been estimated as not greater than four per 1000 exposures. Furthermore, a high percentage of such exposed wornen (30-90\%) have been found to have vaginal adenosis. epithelial changes of the vagina and cervix. Although these
changes are histologically benign, it is not known whether they are precursors of malignancy. Although similar data on the use of other estrogens are not available, it cannot be presumed they would not induce similar changes.

Several reports suggest an association between intrauterine exposure to female sex hormones and congenital anomalies, including congenital heart defects and limb-reduction defects. One case control study estimated a 4.7 -fold increased risk of limb-reduction defects in infants who had been exposed in utero to sex hormones (oral contraceptives, hormone withdrawal tests for pregnancy, or attempted treatment for threatened abortion). Some of these exposures were very short and involved only a few days of treatment. The data suggest that the risk of limb-reduction defects in xposed fetuses is somewhat less than one per 1000

In the past, female sex hormones have been used during pregnancy in an attempt to treat hreatened or habitual abortion. There is considerable evidence that estrogens are ineffective for these indications, and there is no evidence from well-controlled studies that progestogens are

If Estraderm is used during pregnancy. or if the patient becomes pregnant while taking this drug. she should be apprised of the potential risks to the fetus and of the advisability of continuation of the pregnancy.

\section{INDICATIONS AND USAGE}

Estraderm is indicated for the treatment of the following: moderate-to-severe vasomotor symptoms associated with menopause: female hypogonadism; female castration: primary ovarian failure; and atrophic conditions cas

raurosis vulvae.

Studies of the addition of a progestin for seven or more days of a cycle of estrogen administration have reported a lowered incidence of endometrial hyperplasia. Morphological and biochemical studies of endometrium suggest that 12 to 13 days of progestin are needed to provide maximal maturation of the endometrium and to eliminate any hyperplastic changes. Whether this will provide protection from endometrial carcinoma has not been clearly established. There are possible additional risks that may be associated with the inclusion of progestin in estrogen replacement regimens. The potential risks include adverse effects on carbohydrate and lipid metabolism. The choice of progestin and dosage may be important in minimizing these adverse effects.

\section{CONTRAINDICATIONS}

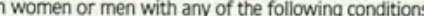

1. known or suspected cancer of the breast:

2. known or suspected estrogen-dependent neoplasia:

3. known or suspected pregnancy (see Boxed Warning):

4. undiagnosed abnormal genital bleeding:

5. active thrombophlebitis or thromboembolic disorders: 6. history of thrombophlebitis, thrombosis, or thromboembolic disorders associated with previous
estrogen use.

\section{WARNINGS}

1. Induction of Malignant Neoplasms. Long-term continuous administration of natural and synthetic liver. There are now reports that estrogens increase the risk of carcinoma of the endometrium in humans. (See Boxed Warning.)

At the present time. there is no satisfactory evidence that estrogens given to postmenopausal women increase the risk of breast cancer. although a recent long-term follow-up of a single physician's practice has raised this possibility. Because of the animal data, there is a need for caution in prescribing estrogens for women with a strong family history of breast cancer or who have breast nodules, fibrocystic disease, or abnormal mammograms.

2. Gallbladder Disease. A recent study has reported a two- to threefold increase in the risk of surgically confirmed gallbladder disease in postmenopausal women receiving oral estrogens, similar to the twofold increase previously noted in users of oral contraceptives.

3. Effects Similar to Those Caused by Estrogen-Progestogen Oral Contraceptives. There are severa shich adverse effects of oral contraceptives and other high-dose oral estrogen treatments, most of therapy. This may reflect the comparatively low doses of estrogen used in postmenopausal women.

a. Ihromboembolic Disease. It is now well established that users of oral contraceptives have an increased risk of various thromboembolic and thrombotic vascular diseases, such as thrombophlebitis. pulmonary embolism, stroke, and myocardial infarction. Cases of retinal thrombosis, mesenteric throm bosis, and optic neuritis have been reported in oral contraceptive users. There is evidence that the risk of several of these adverse reactions is related to the dose of the drug. An increased risk of postsurgery thromboembolic complications has also been reported in users of oral contraceptives. If feasible, estrogen should be discontinued at least four weeks before surgery of the type associated with an increased risk of thromboembolism, or during periods of prolonged immobilization.
While an increased rate of thromboembolic and thrombotic disease in postmenopausal users of estrogens has not been found. this does not rule out the possibility that such an increase may be present or that subgroups of women who have underlying risk factors or who are receiving relatively large doses of estrogens may have increased risk. Therefore. estrogens should not be used in persons with active thrombophlebitis or thromboembolic disorders, and they should not be used in persons with a history of such disorders in association with estrogen use. They should be used with caution in patients with cerebral vascular or coronary artery disease and only for those in whom estrogens are clearly needed.

Large doses of estrogen ( $5 \mathrm{mg}$ conjugated estrogens per day). comparable to those used to treat cancer of the prostate and breast, have been shown in a large prospective clinical trial in men to increase the risk of nonfatal myocardial infarction, pulmonary embolism, and thrombophlebitis. When estrogen doses of this size are used, any of the thromboembolic and thrombotic adverse effects associated with oral b. Hepatic Adenoma benign hepatic adear risk

b. Hepatic Adenoma. Benign hepatic adenomas have been associated with the use of oral contraceptives. Although benign and rare, these turnors may rupture and cause death from intra-abdominal hemorrhage. Such lesions have not yet been reported in association with other estrogen or progestogen preparations, but they should be considered if abdominal pain and tenderness, abdominal mass, or
hypovolemic shock occurs in patients receiving estrogen. Hepatocellular carcinoma has also been reported in wornen taking estrogen-containing oral contraceptives. The causal relationship of this malignancy to these drugs is not known.

c. Elevated Blood Pressure, Women using oral contraceptives sometimes experience increased blood pressure which, in most cases, returns to normal upon discontinuing the drug. There is now a report that chis may occur with use of oral estrogens in the menopause and blood pressure should be monitored with estrogen use, especially if high doses are used. Ethinyl estradiol and conjugated estrogens have been
shown to increase renin substrate. In contrast to these oral estrogens, transdermally administered
estradiol does not affect renin substrate.

d. Glucose Tolerance. A worsening of glucose tolerance has been observed in a significant percentage of patients on estrogen-containing oral contraceptives. For this reason, diabetic patients should be carefully

4. Hypercalcemia. Administration of high doses of estrogens may lead to severe hypercaicemia in patients with breast cancer and bone metastases. If hypercalcemia occurs, use of the drug should be Stopped and appropr

\section{PRECAUT}

1. A complete medical and family history should be taken before initiation of any estrogen therapy. The pretreatment and periodic physical examinations should include special reference to blood pressure. breasts, abdomen, and pelvic organs, as well as a cervical Papanicolaou test. As a general rule, estrogen should not be prescribed for longer than one year without another physical examination being performed.
conditions that might be influenced by this factor are present (e.g. asthma, epilepsy. migraine, and cardiac conditions that might
or renal dysfunction).

3. Certain patients may develop undesirable manifestations of excessive estrogenic stimulation, such as uterine bleeding. mastodynia, etc

4. Prolonged administration of unopposed estrogen therapy has been reported to increase the risk of endometrial hyperplasia in some patients. Estrogens should be used with caution in patients who have or have had endometriosis.

5. Oral contraceptives appear to be associated with an increased incidence of mental depression.
Although it is not clear whether this is due to the estrogenic or progestogenic component of the contraceptive. patients with a history of depression should be carefully observed.

6. Preexisting uterine leiomyomata may increase in size during prolonged estrogen use. If this occurs, estrogen therapy should be discontinued while the cause is investigated.

7. In patients with a history of jaundice during pregnancy, there is an increased risk that jaundice will recur with the use of estrogen-containing oral contraceptives. If jaundice develops in any patient receiving estrogen, the medication should be discontinued while the cause is investigated.

8. Estrogens may be poorly metabolized in patients with impaired liver function and should be

9 . Because the proution in such patients.

9. Because the prolonged use of estrogens influences the metabolism of calcium and phosphorus estrogens should be used with caution in patients with metabolic bone diseases associated with hypercalcemia and in patients with renal insufficiency.

\section{Drug/Laboratory Test Interactions}

The results of certain endocrine and liver function tests may be affected by estrogen-containing ora contraceptives. The following changes have been observed with large doses of oral estrogen:

1. increased sulfobromophthalein retention

increased prothrombin time: increased factors VII. VIII, IX, and X: decreased antithrombin 3 increased norepinephrine-induced platelet aggregability:

Theased thyroxine-binding globulin (TBC). leading to increased circulating total thyroid hormone $\left(\mathrm{T}_{4}\right.$ ) as measured by column or radioimmunoassay: free $T_{3}$ resin uptake is decreased, reflecting the

4. reduced response to the metyrapone test:

5. reduced serum folate concentration:

6. increased serum triglyceride and phospholipid concentration, and decreased pregnanediol excretion. The pathologist should be informed that the patient is receiving estrogen therapy when relevant specimens are submitted.

\section{Carcinogenesis, Mutagenesis, Impairment of Fertility}

WARNINGS and Boxed Warning.

increases the frequenous administration of natural and synthetic estrogens in certain animal species

Pregnancy Category $\mathbf{X}$

CONTRAINDICATIONS and Boxed Warning.

Estrogens should not be used during pregnancy.

\section{Nursing Mothers}

necessary since many drugs are excreted in human milk

\section{ADVERSE REACTIONS}

See WARNINGS and Boxed Warning regarding potential adverse effects on the fetus, induction of malignant neoplasms, increased incidence of gallbladder disease, and adverse effects similar to those of oral contraceptives, including thromboembolism.

The most commonly reported adverse reaction to Estraderm in clinical trials was redness and irritation at the application site. This occurred in about $17 \%$ of the women treated and caused approximately $2 \%$ to discontinue therapy.

The following additional adverse reactions have been reported with estrogenic therapy. including oral contraceptives:

Cenitourinary System: Breakthrough bleeding. spotting. change in menstrual flow: increase in size of

Endocrine: Breast tenderness, breast enlargement.

Gastrointestinal: Nausea, vomiting: abdominal cramps, bloating; cholestatic jaundice have been obEyes: Streepening of therapy.

Ees: Steepening of corneal curvature: intolerance to contact lenses.

scellaneous: Change in weadache, migraine, dizziness.

Do not store above $86^{\circ} \mathrm{F}\left(30^{\circ} \mathrm{C}\right)$.

Do not store unpouched. Apply immediately upon removal from the protective pouch.

CAUTION: Federal law prohibits dispensing without prescription.

\section{I B A}

CIBA Pharmaceutical Company. Division of CIBA-GEIGY Corporation
Summit, New Jersey 07901
109-2778-A 2

C86-55 (Rev. 12/86) 